\title{
Ontogenetic forgetting of stimulus attributes
}

\author{
MATTHEW J. ANDERSON \\ Saint Joseph's College of Maine, Standish, Maine \\ and \\ DAVID C. RICCIO \\ Kent State University, Kent, Ohio
}

\begin{abstract}
The effects of age on the forgetting of stimulus attributes in a differential fear-conditioning paradigm were examined with 18- and 70-day-old rats tested in either the original conditions or shifted stimulating conditions at one of three retention intervals (1, 48, and $120 \mathrm{~h})$. Adults displayed significant shifts at each retention interval, with those tested in the original context displaying greater fear than those tested in the shifted conditions. By contrast, by $48 \mathrm{~h}$ the 18-day-olds had forgotten the specific attributes of the training situation and began treating the two stimulating conditions as functionally equivalent (Experiment 1). In Experiment 2, we tracked the ontogenetic emergence of adult-like memory for stimulus attributes and found a dramatic increase in memory capability by 25 days of age. Experiment 3 illustrated that the forgotten memory attributes of infants may be retrieved by administering a 90 -sec cuing treatment $10 \mathrm{~min}$ prior to the 48-h test. Implications for the phenomenon of infantile amnesia are discussed.
\end{abstract}

The conceptualization of a memory as being composed of numerous parts or attributes has been present in the psychological literature in one form or another for some time (see, e.g., Spear, 1978; Spear \& Riccio, 1994; Underwood, 1969). Although the exact collection of attributes that come together to form our representation or memory of an event is impossible to pinpoint and probably differs across individuals and situations, likely to be included in the assembly is information about the conditioned stimulus (CS), the unconditioned stimulus (US), and the relation between the two; knowledge of reinforcement and appropriate responses; specific spatial information (see, e.g., Olton \& Samuelson, 1976); and information about salient internal (see, e.g., Overton, 1964) and external (see, e.g., Godden \& Baddeley, 1975) cues that happen to be present at training.

According to many of those taking this dynamic multipleattribute view, retrieval of a memory and performance at test are largely influenced by the degree to which the cues available at time of recall correspond to those present during the initial encoding of the memory, with a mismatch of stimulating conditions resulting in retrieval decrement (see, e.g., Carr, 1925; McGeoch, 1942; Spear, 1973; Tulving \& Thomson, 1973). Although it is evident that a mismatch of cues from encoding to retrieval can result in such a decrement (see, e.g., Bower, Monteiro, \& Gilligan, 1978; Davidson, 1987; Ebner, Richardson, \&

Funding of this research was provided by NIMH Grant 37535 to D.C.R. Correspondence concerning this article should be addressed to M. J. Anderson, Psychology Department, Saint Joseph's College of Maine, 278 Whites Bridge Road, Standish, ME 04084-5263 (e-mail: manderson@sjcme.edu).
Riccio, 1981; Holloway \& Wansley, 1973; Smith, 1979; Weingartner, Miller, \& Murphy, 1977), it should be noted that for any information to actually affect the retrieval of a memory, these cues must be encoded along with the target information at time of training (Postman, 1972; Thomson \& Tulving, 1970).

If a memory is in fact made up of many pieces, it is not difficult to imagine that some of these components might be forgotten more rapidly than others. Indeed, in many studies it has been suggested that the memory for stimuli present at training may be forgotten more rapidly than the conditioned response associated with the initial learning, a phenomenon commonly referred to as the forgetting of stimulus attributes (for reviews, see Riccio, Rabinowitz, \& Axelrod, 1994; Riccio, Richardson, \& Ebner, 1984; Spear \& Riccio, 1994).

The commonly observed performance decrement resulting from a shift in stimulating conditions (see, e.g., Godden \& Baddeley, 1975) may be viewed as a form of generalization decrement, whereby training received in one setting fails to generalize to others. As the subject begins to forget the attributes associated with the original training experience, however, a flattening of the generalization gradient may be observed (see, e.g., Perkins \& Weyant, 1958). Responding in the presence of the shifted cues has been shown to increase to a level similar to that observed under the original stimulating conditions as the subject begins to display increased generalization between the two situations (see, e.g., Bahrick, Clark, \& Bahrick, 1967; McAllister \& McAllister, 1963; D. A. Thomas \& Riccio, 1979; D. R. Thomas \& Lopez, 1962; Zhou \& Riccio, 1996). Such flattening of the generalization gradient between the original stimuli and the shifted stimuli has been taken as evidence for the forgetting of stimulus 
attributes (Riccio, Ackil, \& Burch-Vernon, 1992). Interestingly, there is evidence that such forgetting of training stimuli is not permanent and that various pretest reminder treatments are capable of resharpening the memory for the original training and successfully reinstating a shift effect at longer delays (see, e.g., Borovsky \& Rovee-Collier, 1990; Zhou \& Riccio, 1994).

Given that changes in stimulating conditions from training to test have repeatedly been demonstrated to impair test performance and are commonly thought to be one source of forgetting (see, e.g., Carr, 1925; McGeoch, 1942; Spear, 1973; Tulving \& Thomson, 1973; but see also Riccio et al., 1984), it is perhaps not surprising that such a shift effect is thought to be one potential cause of ontogenetic forgetting or infantile amnesia, terms referring to the poorer memories of younger animals in comparison with those of adults (see, e.g., Anderson, Barnes, et al., 2004; Campbell \& Campbell, 1962; Feigley \& Spear, 1970; RoveeCollier, 1999; Schulenburg, Riccio, \& Stikes, 1971; Steinert, Infurna, \& Spear, 1980). Indeed, some have suggested that developmental changes across the retention interval may alter stimulating conditions from time of training to that of test and result in a form of generalization decrement in younger, rapidly developing organisms (see, e.g., Perkins, 1965; for a review, see Campbell \& Spear, 1972). A second potential cause of the limitations of infantile memory capability, however, may be simple physiological immaturity. Data illustrating a lack of infantile amnesia in animals born with relatively mature brains have been put forth (Campbell, Misanin, White, \& Lytle, 1974). In addition, several reports have given accounts of rapid forgetting in immature animals over a period of only a few hours, intervals unlikely to result in substantial changes in stimulating conditions (see, e.g., Anderson, Barnes, et al., 2004; Miller, Jagielo, \& Spear, 1989; Parsons, Fagan, \& Spear, 1973). Although such data suggest that infantile amnesia is likely the product of physiological immaturity, the issue has never been fully resolved.

The purpose of the present series of experiments was to examine the forgetting of training-stimulus attributes as a function of age. Rovee-Collier and her colleagues have offered demonstrations of the forgetting of stimulus attributes in human infants (Borovsky \& Rovee-Collier, 1990; for a review, see Rovee-Collier, 1999); however, these studies are limited in that the developmental period examined is restricted to infancy.

Miller and colleagues have demonstrated age-dependent forgetting of elements of a conditioning episode that do not predict the occurrence of the unconditioned stimulus (Miller et al., 1989; Miller \& Spear, 1989). The paradigm employed in these studies capitalized on the finding that conditioning to a target stimulus (CS+) is enhanced if the subject also experiences another stimulus not paired with the unconditioned stimulus (CS-; see, e.g., Kucharski \& Spear, 1984). By imposing delays between presentation of the $\mathrm{CS}-$ and that of the $\mathrm{CS}+$, age-dependent loss of memory for the $\mathrm{CS}$ - was demonstrated by an impairment in conditioning to the CS + (Miller et al., 1989;
Miller \& Spear, 1989). Although such evidence clearly suggests age-dependent differential forgetting of the various stimuli associated with a training session, one cannot infer from it whether or not there is a delay at which novel stimuli become functionally equivalent to the forgotten original stimuli, nor does it tell us about potential age differences in memory capabilities for contextual cues associated with the training experience. Miller, Jagielo, and Spear (1991) have illustrated that as delays since training increase, novel stimuli can act as reminders of the original training for 18-day-old rats, suggesting that the specific attributes of the original training situation are forgotten for animals of this age. Although this demonstrates that 18-day-old rats do in fact forget the specific attributes of the training situation, which allows for novel stimuli to become functionally equivalent, it tells us little about the influence of ontogeny on such memory capabilities.

Thus, we know surprisingly little about the forgetting of contextual attributes in younger animals in comparison with that of adults. The present experiments were designed to investigate this issue and to further examine the possibility that a generalization decrement or shift effect underlies the phenomenon of infantile amnesia. If this is the case, then immature animals can be expected to be sensitive to explicit context shifts even longer than adults are.

\section{EXPERIMENT 1}

The purpose of this experiment was to examine the effects of ontogeny or development on the forgetting of stimulating conditions present at training. Preweanling (18-day-old) and young adult (approximately 70-day-old) rats were trained in a differential fear-conditioning paradigm in one context (Context A) and tested 1, 48, or $120 \mathrm{~h}$ later in either the original context or a new, shifted context (Context B).

\section{Method}

Subjects. The subjects were 6018 -day-old (preweanling) and 60 approximately 70 -day-old (adult) male rats derived from the Long-Evans strain $(N=120)$ and maintained on a 12-h light:dark schedule. All of the animals were born, bred, and housed in the Kent State University psychology department animal facilities in standard plastic cages and maintained on ad lib food and water throughout the experiment. The preweanling and adult animals were obtained 3 days prior to their 18th or approximately their 70th day after birth, respectively. The animals in the preweanling group were housed in standard plastic cages with their mothers and female littermates until after testing. The animals in the adult group were housed with multiple animals per cage in order to maintain relative consistency in housing numbers across groups and to control for any effect that differences in housing number might produce.

Materials. Training and testing apparatuses consisted of two $42.5 \times 17.5 \times 18.75-\mathrm{cm}$ two-compartment chambers, each with a guillotine doorway in the middle separating a white compartment from a black compartment. Each apparatus was set up on a table in one of two different rooms (Context A and Context B). All training took place in Context $\mathrm{A}$, in which the chamber was placed on a floor of steel rods $2 \mathrm{~mm}$ in diameter spaced approximately $1 \mathrm{~cm}$ apart. This flooring allowed the administration of $0.5-\mathrm{mA}$ intensity shocks from a constant current AC shock generator (Model 5806, 
Lafayette Instruments, Lafayette, IN). Context A was illuminated with a $25-\mathrm{W}$ red lightbulb, which was hung approximately $3 \mathrm{ft}$ above the chamber and was scented with a Glade PlugIn (Mountain Berry scent) that was refilled once a week. This context also contained white noise provided by a Philco AM/FM cassette recorder (Model $588 \mathrm{~K}$, Kmart, Troy, MI). Context B, on the other hand, contained no experimentally introduced noise or scent and was illuminated by standard fluorescent overhead lighting. The testing chamber in this context was placed on a sheet of clear Plexiglas. Thus, the stimulus conditions provided by the two contexts differed in terms of olfactory, visual, auditory, and cutaneous sensory cues.

Procedure. The animals in each age group were randomly assigned to cells, with a minimum of six different litters represented in each group. All animals from each of the two age groups $(n=$ 60 ) were handled for approximately $3 \mathrm{~min} /$ day for 3 consecutive days and then received training in a Pavlovian differential fearconditioning task in Context A. The chosen fear-conditioning procedure involved pairing the black side of the two-compartment chamber with a mild footshock so that the animal became afraid of that part of the apparatus. Since rats naturally prefer the dark compartment, a later preference for the white (safe) side was interpreted as evidence of aversion to or fear of the black side.

Each animal was brought into Context A and handled for $30 \mathrm{sec}$, to allow the animal the opportunity to adjust to the new light conditions and thoroughly experience the context. Following this 30 -sec adaptation period, each subject was placed in the white side of the two-compartment apparatus. After a brief $(15-\mathrm{sec})$ period on the white (safe) side of the chamber, a guillotine doorway separating the two compartments was opened, allowing the rat to cross to the black side. The latency (in seconds) of the animal to cross into the black side was recorded. Once the animal had crossed, the guillotine door closed and the animal received two brief (1-sec) inescapable footshocks, each with an intensity of $0.5 \mathrm{~mA}$, separated by an interval of $5 \mathrm{sec}$. Five seconds after the second shock, the animal was returned to its home cage.

Following its respective retention interval $(1,48$, or $120 \mathrm{~h} ; n=$ 40 ), each animal underwent testing in either the original training context or the shifted context. At test, each animal was brought into the context and again handled for $30 \mathrm{sec}$. Following this adjustment period, the rat was placed in the white side of the testing chamber and the guillotine door immediately opened. The subject remained in the apparatus for $10 \mathrm{~min}$, to have an opportunity to choose between the fearful and nonfearful cues (i.e., one of two compartments had never been associated with shock and was "safe"). Latency to cross into the black side was again recorded, as was the total amount of time spent on the safe side of the apparatus. Two 2 (context) $\times 2$ (age) $\times 3$ (delay) ANOVAs were conducted to examine both the mean test cross latencies and mean total time spent on the safe side of each cell $(n=10 /$ cell; $N=120)$.

\section{Results and Discussion}

The 2 (context) $\times 2$ (age) $\times 3$ (delay) ANOVA on mean test cross latency yielded significant main effects of age $[F(1,108)=94.232, p<.05]$, context $[F(1,108)=43.510$, $p<.05]$, and delay $[F(2,108)=11.974, p<.05]$. In addition, significant age $\times$ context $[F(2,108)=10.659, p<$ $.05]$, age $\times$ delay $[F(2,108)=6.436, p<.05]$, and age $\times$ context $\times$ delay $[F(2,108)=3.164, p<.05]$ interactions were found. No significant context $X$ delay interaction was found $(p>.05)$. Given that the test cross latencies yielded a significant three-way interaction, Tukey HSD multiple comparison procedures were employed to examine group differences on that measure.

Figure 1 shows the mean test cross latencies of each group. The data obtained with this measure strongly suggest age-dependent differential forgetting of the stimulating conditions present at training. Importantly, the lack of a difference between 18-day-old and 70-day-old animals tested in the original training context at the 1-h delay $(d=$ $0.57, p>.05)$ suggests that animals of both ages are initially displaying similar amounts of learning. This outcome discounts the possibility that the age differences observed at the longer intervals are simply the result of differences in activity levels or some other performance effect.

Since a great deal of data suggest that the hippocampi of younger rats are not yet fully developed and that, therefore, pups do not easily encode contextual information (see, e.g., Rudy, 1993), one of the concerns in the present experiment was that a significant shift effect in the younger

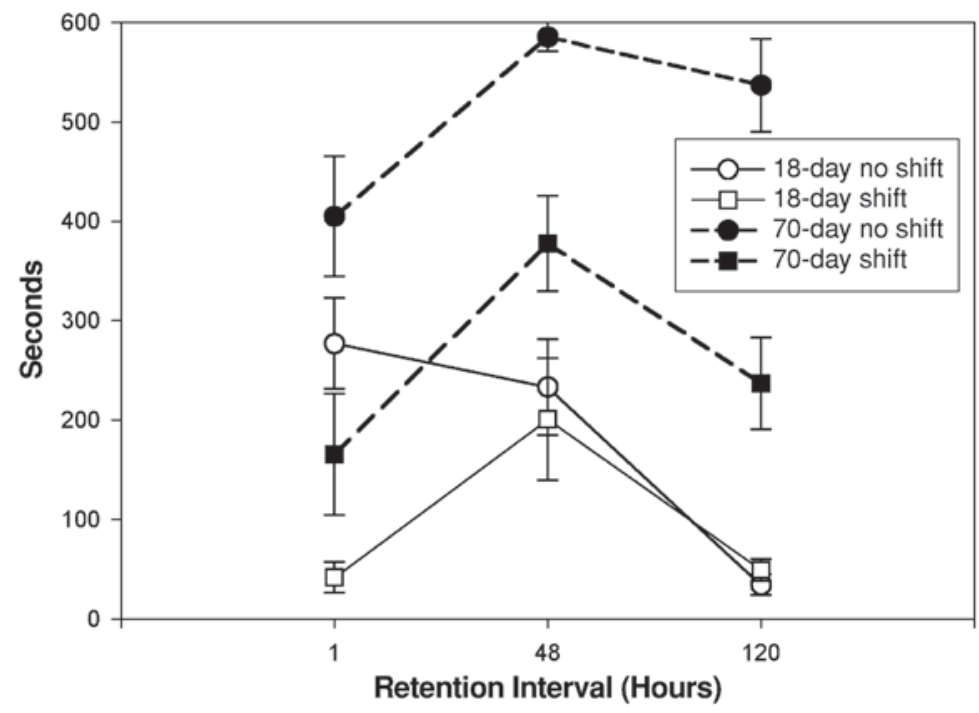

Figure 1. Experiment 1: Mean test cross latencies (and standard errors of the means) of each age at each retention interval. 
animals would not be observed. This clearly was not the case, since significant shift effects were observed for both the adults and the pups at the 1-h retention interval $(p<$ $.05)$. These findings are a prerequisite to any claim of age differences in memory for stimulus attributes.

The obtained test cross latency data of those animals tested in the original training context at the various retention intervals nicely replicate the ontogenetic forgetting that has been demonstrated many times in the literature (see, e.g., Anderson, Barnes, et al., 2004; Campbell \& Campbell, 1962). Although we found no significant differences in initial learning, evidenced by a lack of age differences in cross latency at $1 \mathrm{~h}$ in the original training context $(p>.05)$, by $48 \mathrm{~h}$ the adults were clearly showing better retention of fear than the infants. Indeed, at both the 48- and the 120-h retention intervals, the adults tested in the presence of the original stimulating conditions reliably outperformed their younger counterparts $(p<.05)$.

Age-dependent differential forgetting of stimulus attributes could have been evidenced in one of two ways. First, such ontogenetic forgetting could have manifested itself by a more dramatic increase in fear (as measured by longer test cross latencies) in the shifted context from $1 \mathrm{~h}$ to 48 or $120 \mathrm{~h}$ in pups but not in adults. Second, as long as a significant shift effect was obtained at $1 \mathrm{~h}$, a loss of significant differences between same-context and shiftedcontext test groups at a longer interval for the pups but not for the adults could also have served as an indicator of ontogenetic forgetting. This index, however, would be valid only if no significant differences were detected between the pups tested in the same context at $1 \mathrm{~h}$ and those tested in the training context at the long delay, at which the shift is lost. For animals of either age, a significant drop in test cross latency and total time on the safe side from $1 \mathrm{~h}$ to a longer delay by subjects tested in the original stimulating conditions (Context A) would be evidence of a loss of memory for the response (i.e., avoidance of fear-evoking black) and could not be interpreted as a loss of memory for training-stimulus attributes.

The latter of these two possibilities was observed in the present experiment. Across all retention intervals, the adults displayed significant shift effects: Those tested in the original training context had higher test cross latencies than those tested in the shifted condition $(p<.05)$. The pups displayed such a significant shift effect $(p<$ .05 ) only at $1 \mathrm{~h}$; indeed, by $48 \mathrm{~h}$ the shift effect was lost for the 18-day-olds $(p>.05)$. It is worth noting that pup performance in the original stimulating conditions did not drop significantly from $1 \mathrm{~h}$ to $48 \mathrm{~h}$, suggesting that the flat generalization gradient does indeed represent the forgetting of stimulus attributes and is not likely the result of a loss of memory for the appropriate avoidance response $(d=0.19, p>.05)$. Moreover, although there was a significant increase in adult test cross latencies in the shifted condition from $1 \mathrm{~h}$ to $48 \mathrm{~h}(p<.05)$, the significant shift effect was never lost $(p>.05)$. Taken together, these results suggest that the preweanlings forgot the specific at- tributes of the training situation and began treating new stimuli as if they were the originals at a much more rapid rate than did the adults.

In general, the 2 (context) $\times 2$ (age) $\times 3$ (delay) ANOVA on mean total time spent on the safe side of each cell produced results similar to those of the ANOVA on test cross latency. Significant main effects of age $[F(1,108)=$ $45.193, p<.05]$, context $[F(1,108)=67.640, p<.05]$, and delay $[F(2,108)=5.073, p<.05]$ were found. In addition, a significant age $\times$ delay interaction was observed $[F(2,108=3.749, p<.05]$. Again, no significant context $\times$ delay interaction was found $(p>.05)$. Unlike the latency measure, however, the total time data did not yield significant age $\times$ context or age $\times$ context $\times$ delay interactions $(p>.05)$.

Although the lack of significant effects on total time spent on the safe side may appear to be inconsistent with the latency variables, the difference might be accounted for by a reminder treatment that would seem inherent to measures of total time on the safe side. To put it simply, perhaps after crossing to the unsafe side once, the subject is reminded of the previous shock presentation and leaves the area, spending the majority of the remaining time in the white side. Since steep generalization gradients were obtained for both ages at each delay when this measure was employed in the present experiment, this seems likely to be the case. Recent studies (conducted in our laboratory) of attribute forgetting have produced similar results, with measures of cross latency (but not those of total time on the safe side) indicating a flattened generalization gradient at intermediate delays (Millin, 2003). Investigations conducted in other laboratories have led to similar conclusions (see, e.g., Santucci \& Cardiello, 2004), suggesting that test cross latency is likely the better indicator of memory at test.

\section{EXPERIMENT 2}

In Experiment 2, we attempted to track the ontogenetic emergence of adult-like memory for training-stimulus attributes. Relying on the retention interval ( $48 \mathrm{~h})$ identified in Experiment 1, in which infants but not adults forgot the stimulating conditions associated with the original training, we tested preweanling through young adult rats to determine the age at which the animals begin to display more adult-like memory capabilities.

\section{Method}

Subjects. The subjects were 18-day-old, 25-day-old, 45-day-old, and approximately 70-day-old male rats derived from the LongEvans strain $(N=96)$. There were 24 subjects in each of the four age groups. They were obtained and maintained exactly as were the animals in the previous experiment. The four selected ages were purposefully skewed toward infancy to take into account the particularly rapid rate of development in younger animals in comparison with older ones.

Materials. All apparatuses and contexts were identical to those described in Experiment 1. 
Procedure. The animals were randomly assigned to cells and handled as described for Experiment 1. They received training in the differential fear-conditioning task in the exact manner as in Experiment 1.

Forty-eight hours later, all the animals underwent testing in either the original training context (Context A) or the shifted context (Context B). Testing occurred according to the method previously described, with one exception. Since in Experiment 1 a large number of the adults were at ceiling (i.e., failed to cross into the black side for the entire 10-min test) at the 48-h retention interval, the duration of the test session in this experiment was increased to $15 \mathrm{~min}$. This was done in an attempt to more accurately depict age-related differences in memory at this retention interval. Two 2 (context) $\times 4$ (age) ANOVAs were conducted to examine both the mean test cross latencies and mean total time spent on the safe side for each cell $(n=12 /$ cell; $N=96)$.

\section{Results and Discussion}

The purpose of this experiment was to begin to determine the nature of the onset of adult-like memory for stimulus attributes. More specifically, we sought to judge whether there is a specific ontogenetic point at which rats begin to act like adults or if, instead, such memory develops more gradually across the life span.

The 2 (context) $\times 4$ (age) ANOVA on mean test cross latencies yielded significant main effects of age $[F(3,88)=$ $4.178, p<.05]$ and context $[F(1,88)=58.708, p<.05]$ as well as a significant age $\times$ context interaction $[F(3,88)=$ $5.426, p<.05]$. Tukey HSD multiple comparison procedures were again employed to examine group differences in mean test cross latency.

Figure 2 shows the mean test cross latencies of each group. The latency measures reveal a significant shift effect for all ages $(p<.05)$ except the 18-day-olds $(p>$ .05 ). Indeed, the animals in the youngest age group displayed an extremely flat generalization gradient, responding in the presence of the shifted stimuli as if they were unchanged. Thus, a partial replication of the major find- ings from the first experiment was successfully obtained. In addition, the 18-day-old no-shift group displayed significantly lower test cross latencies than did the 25-, 45-, and 70-day-old no-shift groups $(p<.05)$. Taken together, these findings indicate a marked increase in memory capability between 18 and 25 days of age. Specifically, memory for the appropriate response as well as memory for training-stimulus attributes would appear to be greatly enhanced and much more adult by 25 days of age, at least at a 48 -h retention interval.

The 2 (context) $\times 4$ (age) ANOVA on mean total time spent on the safe side of each cell produced quite different results. Only a significant main effect of context $[F(1,88)=82.543, p<.05]$ was found. Neither a significant main effect of age nor a significant age $\times$ context interaction was found $(p>.05)$. Since a significant age $\times$ context interaction would be needed for examination of the differences of interest, no multiple comparison procedures were calculated.

The only significant effect according to the ANOVA on mean total time on the safe side was a main effect of context. This finding suggests that a shift effect is present regardless of age and is consistent with the notion that the measure of total time on the safe side may entail an inherent reminder treatment. Such a reminder treatment could easily abolish the age differences observed with the initial test cross latency measure. Again, given that the test cross latency measure contains no such flaw, it is likely the better indicator of memory at test.

Further research is needed to examine additional retention intervals, but the present findings are consistent with those of previous studies suggesting dramatic improvements in memory capacity during this early developmental window (e.g., Anderson, Moody, Miner, \& Riccio, 2002; Campbell et al., 1974). Many have suggested that this period is also one of rapid physiological change.

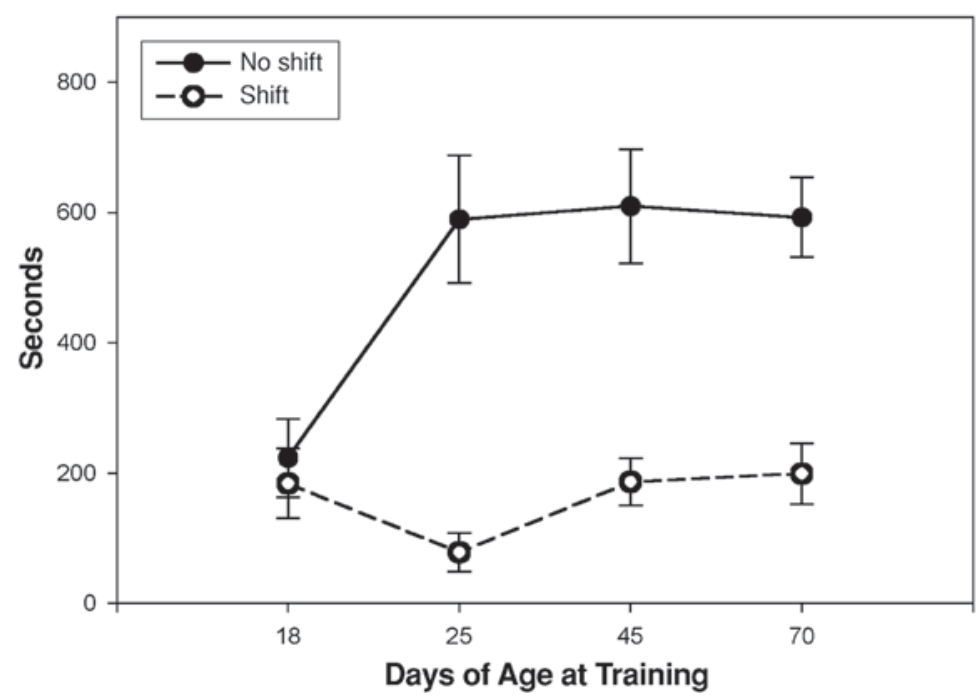

Figure 2. Experiment 2: Mean test cross latencies (and standard errors of the means) of each age at the 48 -h retention interval. 
Indeed, both a dramatic increase in neocortical synaptic density (see, e.g., Aghajanian \& Bloom, 1967) and rapid hippocampal maturation (see, e.g., Altman, Brunner, \& Bayer, 1973) are associated with this developmental period. It is likely that such rapid structural developments enable the more adult-like performance that is observed in the 25-day-old subjects.

\section{EXPERIMENT 3}

Using a differential fear-conditioning task similar to that used in the present study, Zhou and Riccio (1994) showed that the forgetting of stimulus attributes by adult rats can be alleviated by a pretest cuing treatment. Similarly, Borovsky and Rovee-Collier (1990) demonstrated in human infants that the loss of memory for training-stimulus attributes is reversible with pretest reminders. The primary purpose of the final experiment was to examine the permanence of the ontogenetic forgetting of contextual attributes in our differential fear-conditioning paradigm. In this experiment, we adopted methods similar to those of Zhou and Riccio (1994) to examine the effectiveness of a contextual reminder treatment in the alleviation of the forgetting of training-stimulus attributes in 18-day-old rats.

Many researchers employing similar tasks have found differences in the capabilities of adult male and female rats, with adult males typically displaying significantly better performance than their female counterparts (see, e.g., Pryce, Lehmann, \& Feldon, 1999; Van Oyen, Van de Poll, \& de Bruin, 1979). A secondary purpose of this experiment was to examine possible sex differences by comparing male and female pups at the 48 -h retention interval.

\section{Method}

Subjects. The subjects were forty-eight 18-day-old rats derived from the Long-Evans strain, obtained and maintained as were those in the previous experiments. Of the 48 animals, 24 were males and 24 were females.

Materials. All apparatuses and contexts used in the present experiment have been described for the earlier experiments, with one exception. In Context A, a clear Plexiglas standard cage was placed on the table next to the conditioning chamber. This cage was placed in such a manner that it was parallel to and approximately 3 in. away from the conditioning apparatus.

Procedure. The animals were handled and then trained in the differential fear-conditioning task in Context $\mathrm{A}$ according to the methods described in Experiment 1. Eight groups of rats differing in sex, testing context, and reminder treatment were run in this experiment $(n=6)$.

Two groups of pups of each sex received no reminder treatment and waited the entire 48-h retention interval in their home cages with their mothers and littermates. These animals were simply tested as previously described - one group in Context A, the other in Context B-at the 48-h retention interval that was identified in Experiment 1 to result in forgetting of stimulus attributes in infants but not in adults.

The remaining four groups of pups, two of each sex $(n=6)$, received a contextual reminder/pretest cuing treatment. This reminder treatment consisted of being placed in the clear Plexiglas cage located next to the conditioning chamber in the original training con- text for $90 \mathrm{sec}$. During this period, the animal had the opportunity to take in the sights, sounds, and smells of the training context and view the conditioning chamber. Approximately $10 \mathrm{~min}$ after this reminder ( $48 \mathrm{~h}$ after training), these animals underwent testing in either the original training context or the shifted context.

Testing took place exactly as described in Experiment 1. Since in both previous experiments the infants tested at the 48-h retention interval failed to reach ceiling, the test period was lowered to $10 \mathrm{~min}$. Two 2 (sex) $\times 2$ (context) $\times 2$ (reminder treatment) ANOVAs were conducted to examine both mean test cross latencies and mean total time spent on the safe side of each cell $(n=6 /$ cell; $N=48)$.

\section{Results and Discussion}

The main purpose of the present experiment was to examine the permanence of the ontogenetic forgetting of stimulus attributes in our differential fear-conditioning paradigm. Both Zhou and Riccio (1994), examining adult rats in a similar task, and Borovsky and Rovee-Collier (1990), investigating human infants in the conjugate reinforcement paradigm, have shown that age-dependent loss of memory for training-stimulus attributes is reversible with pretest reminders. Perhaps not surprisingly, the outcome of the present experiment was highly consistent with these results as well as with those of the many studies illustrating that forgetting of a learned response is not irreversible in young animals (e.g., Campbell \& Jaynes, 1966; Spear \& Parsons, 1976; Spear \& Smith, 1978).

The 2 (sex) $\times 2$ (context) $\times 2$ (reminder treatment) ANOVA on the mean test cross latencies and mean total time spent on the safe side of each cell revealed a significant main effect of context $[F(1,40)=19.169, p<$ $.05]$ and a significant context $\times$ reminder interaction $[F(1,40)=10.111, p<.05]$. No other significant results were obtained $(p>.05)$. Tukey HSD multiple comparison procedures were employed to further examine group differences in mean test cross latency for the significant context $\times$ reminder interaction, collapsing across sex.

The mean test cross latencies of each group are depicted in Figure 3. It is clear that the pups that received reminders had much greater success retrieving the memory for the stimulating conditions associated with the original training. This is evidenced by a lack of a shift effect for those that did not receive the reminder $(p>.05)$ and a dramatic shift for those that did $(p<.05)$. Moreover, the reminder not only resharpened memory for stimulating conditions but also enhanced memory for the avoidance response. This is evidenced by significantly larger test cross latencies for the reminder/no-shift group in comparison with the no-reminder/no-shift group $(p<.05)$. Thus, it appears that the forgotten memory attributes of the infant animals are not lost and may, under certain conditions, be retrieved, allowing the animals to distinguish between the original and the shifted stimuli once more.

The $2(\operatorname{sex}) \times 2$ (context) $\times 2$ (reminder treatment $)$ ANOVA on mean total time spent on the safe side of each cell also revealed a significant main effect of context $[F(1,40)=71.333, p<.05]$ and a significant context $\times$ reminder interaction $[F(1,40)=4.847, p<.05]$. Again, no other significant results were obtained $(p>.05)$. 


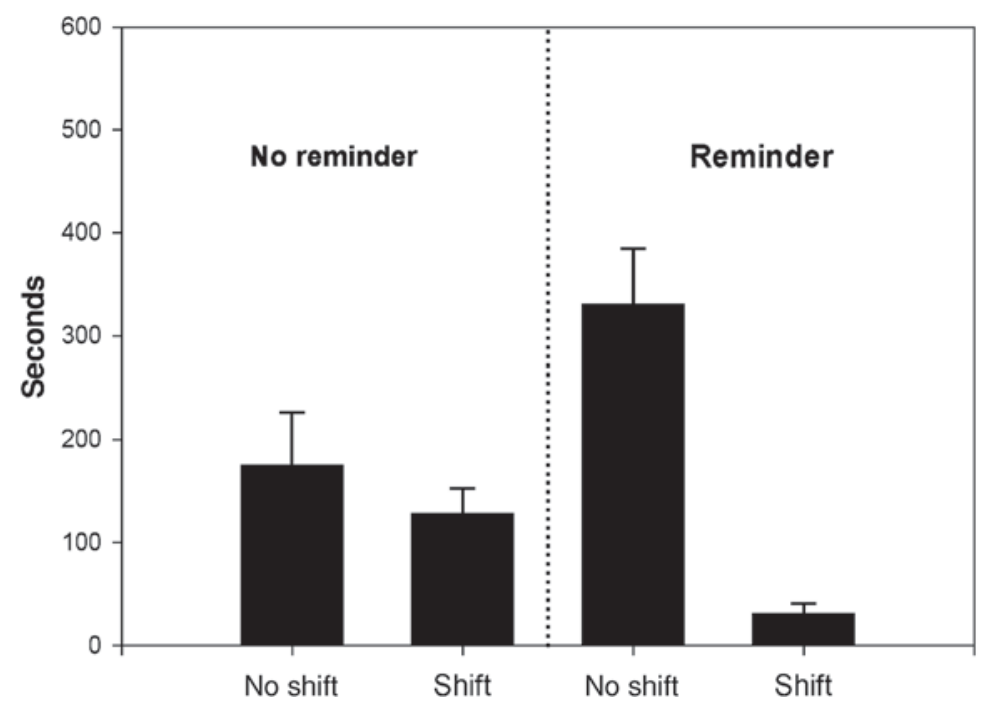

Figure 3. Experiment 3: Mean test cross latencies (and standard errors of the means) of each group at the 48 -h retention interval.

Tukey HSD multiple comparison procedures were employed to further examine group differences in mean total time on the safe (white) side for the significant context $X$ reminder interaction, collapsing across sex.

The measures of mean total time on the safe side for each group can be seen in Figure 4. The significant total time on the safe side context $\times$ reminder interaction suggests that the reminder affected this measure as well. Although a significant shift was observed for both reminded and nonreminded animals $(p<.05)$, the generalization gradient of those receiving the cuing treatment appears to be slightly steeper. This suggests that the planned reminder may simply be adding to the already existing reminder that is thought to be inherent to the measure of total time on the safe side (see, e.g., Millin, 2003; Santucci \& Cardiello, 2004). Again, it would seem that test cross latency is a better indicator of memory for training.

A secondary purpose of this experiment was to begin to examine any possible sex differences in retention of training attributes at 18 days of age. Numerous studies involving a variety of tasks (e.g., Pryce et al., 1999; Van Oyen et al., 1979) have shown differences in the capabilities of adult male and female rats. Neither the ANOVA on test cross latency nor the analysis of total time on the safe side revealed a significant main effect of sex or any significant sex $\times$ context, sex $\times$ reminder, or sex $\times$ context $\times$ reminder interaction $(p>.05)$. Assuming that pups of both sexes started with similar amounts of initial learning, our

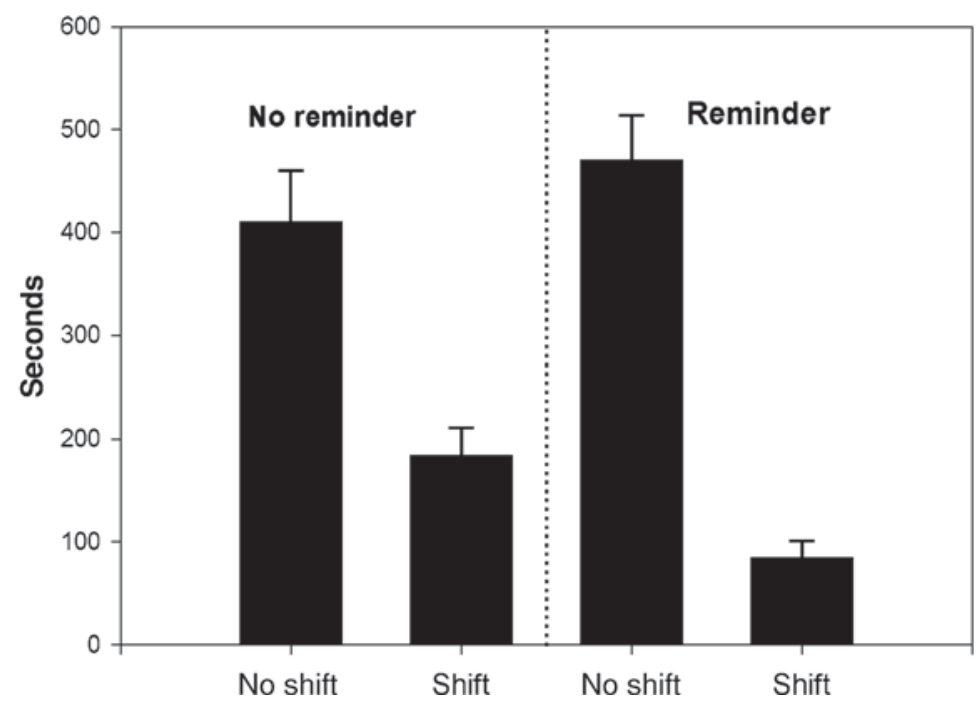

Figure 4. Experiment 3: Mean total time on the safe (white) side measures (and standard errors of the means) for each group at the 48 -h retention interval. 
data suggest a lack of sex differences in memory for training attributes at 18 days of age.

\section{GENERAL DISCUSSION}

In order to comprehend better the workings of memory from infancy to adulthood, in the present series of experiments we examined the effects of development on the forgetting of training-stimulus attributes. In Experiment 1, we investigated the issue in a differential fear-conditioning paradigm with preweanling and young adult rats tested at three different retention intervals $(1,48$, and $120 \mathrm{~h})$ in the presence of either the original conditions or shifted stimulating conditions. Although no age differences were found in initial learning about the response or the context, the 18-day-olds displayed increased generalization between the original and the shifted cues by $48 \mathrm{~h}$, evidence that they had forgotten the specifics of the original stimulating conditions. Adult animals displayed no such loss of discriminability, showing significant shift effects at all intervals examined. Such differences suggest an agedependent forgetting of stimulus attributes.

In Experiment 2, we tracked the ontogenetic emergence of adult-like memory capabilities with 18-, 25-, 45-, and approximately 70 -day-old rats trained in the same manner as those in Experiment 1 and tested at the 48-h retention interval in either the original conditions or shifted conditions. Mean test cross latency scores indicate a significant shift effect for all ages except the 18-day-olds, which displayed a very flat generalization gradient, responding in the presence of the shifted cues as if these were the original cues. These findings indicate a dramatic increase in memory capability between 18 and 25 days of age, which is consistent with previous studies suggesting marked improvements in other memory capacities during this early developmental window (e.g., Anderson et al., 2002; Campbell et al., 1974).

Many studies (e.g., Anderson, Karash, \& Riccio, 2004; Borovsky \& Rovee-Collier, 1990) have illustrated that rapid memory loss associated with infancy is not irreversible, suggesting that such forgetting may be the result of a retrieval failure (Spear, 1973) rather than the product of a decay-like process. Relying on methods similar to those used by Zhou and Riccio (1994), in Experiment 3 we investigated the permanence of the ontogenetic forgetting of stimulus attributes by administering a 90 -sec cuing treatment 10 min prior to the 48 -h test. Animals receiving the cuing treatment displayed not only resharpened memory for the stimulus attributes associated with the original training, but also enhanced memory for the avoidance response. It was concluded from this experiment that the stimulus attributes forgotten by the infant animals are not lost from storage and may, under appropriate conditions, be retrieved.

Taken together, the results of these experiments suggest an age-dependent loss of memory specificity with younger animals, which forget the specific attributes associated with training at a faster rate than do adults. Riccio et al. (1994) explored the many methodological and conceptual implications of the forgetting of attributes, suggesting that a variety of psychological phenomena, cognitive failures, and distortions may indeed be the result of such loss of specificity. In particular, the malleability of memory for eyewitnessed episodes (see, e.g., Loftus, 1992) as well as difficulties in reality/source monitoring (Intraub \& Hoffman, 1992; Johnson, Hashtroudi, \& Lindsay, 1993; Johnson \& Raye, 1981; Suengas \& Johnson, 1988) seem likely to be dependent on the forgetting of stimulus attributes over time. The present data would suggest that such cognitive failures and distortions might in fact be much worse for younger animals than for older ones. While examining the malleability of human memory, Ackil and Zaragoza (1998) also suggested this to be the case.

For some time, many authors have recognized two potential causes of infantile amnesia (e.g., Campbell \& Campbell, 1962; Campbell \& Spear, 1972; Spear, 1978). First, developmental changes across the retention interval may alter stimulating conditions from time of training to that of test and result in a form of generalization decrement. Second, simple physiological immaturity may account for the limitations of infantile memory capabilities. The present results discount the potential contribution of a generalization decrement to infantile amnesia. Since, as we have shown, the responding of infant animals generalizes to shifted stimuli at a faster rate than does the responding of adults, it is unlikely that a generalization decrement plays any causal role in poor infantile memory. These findings, along with data illustrating a lack of infantile amnesia in animals born with relatively mature brains (see, e.g., Campbell et al., 1974) and evidence of infantile amnesia over very short retention intervals that are not likely to result in substantial changes in stimulating conditions (see, e.g., Anderson, Barnes, et al., 2004; Miller et al., 1989; Parsons et al., 1973), suggest that infantile amnesia is likely the product of simple physiological immaturity at the time of encoding and not some form of generalization decrement.

Given that many have demonstrated that learning about contextual information is dependent on the hippocampus (e.g., Kim, Rison, \& Fanselow, 1993; Phillips \& LeDoux, 1992), hippocampus immaturity would seem the most obvious cause of the observed age differences (see, e.g., Altman et al., 1973; Rudy, 1993). However, other possible explanations of the present results must also be considered. For instance, many have noted that the hypothalamicpituitary-adrenal (HPA) system, which facilitates adaptation to environmental stress, is underdeveloped in younger animals (e.g., Meaney, Sapolsky, \& McEwen, 1985; Pryce, Palme, \& Feldon, 2002). Indeed, rats with underdeveloped HPA systems have been shown to have hyporesponsive pituitary-adrenal hormone responses to events that elicit marked stress responses in older animals (see, e.g., Sapolsky \& Meaney, 1986). Moreover, adrenalectomy or pharmacological blockade of glucocorticoid receptors in adult rats, effectively rendering them more infantile in HPA functioning, has been shown to impair memory consolidation in contextual fear-conditioning paradigms (Pugh, Fleshner, \& Rudy, 1997; Pugh, Tremblay, Fleshner, 
\& Rudy, 1997). It has also been shown that the number of glucocorticoid receptors present in the rat hippocampus does not reach adult levels until the end of the third week after birth (Meaney \& Aitken, 1985; Rosenfeld, Sutanto, Levine, \& de Kloet, 1988; Sarrieau, Sharma, \& Meaney, 1988). This increase appears to be correlated with the emergence of adult-like memory capabilities in the present studies. Perhaps the underdeveloped hippocampal and HPA systems of the young rats in the present experiments jointly account for the rapid contextual generalization of fear. Future research is necessary to explore this possibility and to further examine the biology underlying such ontogenetic forgetting of stimulus attributes.

\section{REFERENCES}

ACKIL, J. K., \& ZaRAGOZA, M. S. (1998). Memorial consequences of forced confabulation: Age differences in susceptibility to false memories. Developmental Psychology, 34, 1358-1372.

Aghajanian, G. K., \& Bloom, F. E. (1967). The formation of synaptic junctions in developing rat brain: A quantitative electron microscopic study. Brain Research, 6, 716-727.

Altman, J., Brunner, R. L., \& Bayer, S. A. (1973). The hippocampus and behavioral maturation. Behavioral Biology, 8, 557-596.

Anderson, M. J., Barnes, G. W., Briggs, J. F., Ashton, K. M., Moody, E. W., Joynes, R. L., \& Riccio, D. C. (2004). The effects of ontogeny on the performance of rats in a novel object recognition task. Psychological Reports, 94, 437-443.

Anderson, M. J., Karash, D. L., \& Riccio, D. C. (2004). The alleviation of ontogenetic forgetting in a novel object recognition task. Journal of Behavioral \& Neuroscience Research, 2, 1-5.

Anderson, M. J., Moody, E. W., Miner, C., \& Riccio, D. C. (2002, May). Assessment of ontogeny and infantile amnesia through novel object recognition. Poster presented at the annual meeting of the Midwestern Psychological Association, Chicago.

Bahrick, H. P., Clark, S., \& Bahrick, P. (1967). Generalization gradients as indicants of learning and retention of a recognition task. Journal of Experimental Psychology, 75, 464-471.

Borovsky, D., \& Rovee-Collier, C. (1990). Contextual constraints on memory retrieval at six months. Child Development, 61, 1569-1583.

Bower, G. H., Monteiro, K. P., \& Gilligan, S. G. (1978). Emotional mood as a context for learning and recall. Journal of Verbal Learning \& Verbal Behavior, 17, 573-585.

Campbell, B. A., \& Campbell, E. H. (1962). Retention and extinction of learned fear in infant and adult rats. Journal of Comparative \& Physiological Psychology, 55, 1-8.

Campbell, B. A., \& Jaynes, J. (1966). Reinstatement. Psychological Review, 73, 478-480.

Campbell, B. A., Misanin, J. R., White, B. C., \& Lytle, L. D. (1974). Species differences in ontogeny of memory: Indirect support for neural maturation as a determinant of forgetting. Journal of Comparative \& Physiological Psychology, 87, 193-202.

Campbell, B. A., \& Spear, N. E. (1972). Ontogeny of memory. Psychological Review, 79, 215-236.

CARr, H. A. (1925). Psychology: A study of mental activity. New York: Longmans, Green.

DAVIDSON, T. L. (1987). Learning about deprivation intensity stimuli. Behavioral Neuroscience, 101, 198-208.

EBNER, D. L., Richardson, R., \& Riccio, D. C. (1981). Ovarian hormones and retention of learned fear in rats. Behavioral \& Neural Biology, 33, 45-58.

Feigley, D. A., \& Spear, N. E. (1970). Effect of age and punishment condition on long-term retention by the rat of active- and passiveavoidance learning. Journal of Comparative \& Physiological Psychology, 73, 515-526.

GodDEn, D. R., \& BADDEley, A. D. (1975). Context-dependent memory in two natural environments: On land and underwater. British Journal of Psychology, 66, 325-331.

Holloway, F. A., \& WANSLEY, R. (1973). Multiphasic retention deficits at periodic intervals after passive-avoidance learning. Science, 180, 208-210.

Intraub, H., \& Hoffman, J. E. (1992). Reading and visual memory: Remembering scenes that were never seen. American Journal of Psychology, 105, 101-114.

Johnson, M. K., Hashtroudi, S., \& Lindsay, D. S. (1993). Source monitoring. Psychological Bulletin, 114, 3-28.

Johnson, M. K., \& RAYE, C. L. (1981). Reality monitoring. Psychological Review, 88, 67-85.

Kim, J. J., Rison, R. A., \& FAnselow, M. S. (1993). Effects of amygdala, hippocampus, and periaqueductal gray lesions on short- and longterm contextual fear. Behavioral Neuroscience, 107, 1093-1098.

Kucharski, D., \& Spear, N. E. (1984). Conditioning of aversion to an odor paired with peripheral shock in the developing rat. Developmental Psychobiology, 17, 465-479.

Loftus, E. F. (1992). When a lie becomes memory's truth: Memory distortion after exposure to misinformation. Current Directions in Psychological Science, 1, 121-123.

MCAllister, W. R., \& McAllister, D. E. (1963). Increase over time in the stimulus generalization of acquired fear. Journal of Experimental Psychology, 65, 576-582.

McGeoch, J. A. (1942). The psychology of human learning: An introduction. New York: Longmans, Green.

Meaney, M. J., \& AitKen, D. H. (1985). The effects of early postnatal handling on hippocampal glucocorticoid receptor concentrations: Temporal parameters. Brain Research, 354, 301-304.

Meaney, M. J., SAPOLsKy, R. M., \& McEwen, B. S. (1985). The development of the glucocorticoid receptor system in the rat limbic brain: I. Ontogeny and autoregulation. Brain Research, 350, 159-164.

Miller, J. S., Jagielo, J. A., \& Spear, N. E. (1989). Age-related differences in short-term retention of separable elements of an odor aversion. Journal of Experimental Psychology: Animal Behavior Processes, 15, 194-201.

Miller, J. S., Jagielo, J. A., \& Spear, N. E. (1991). Differential effectiveness of various prior-cuing treatments in the reactivation and maintenance of memory. Journal of Experimental Psychology: Animal Behavior Processes, 17, 249-258.

Miller, J. S., \& Spear, N. E. (1989). Ontogenetic differences in shortterm retention of Pavlovian conditioning. Developmental Psychobiology, 22, 377-387.

MILLIN, P. M. (2003). Is the context shift effect a case of retrieval failure? The effects of retrieval enhancing treatments on forgetting under altered stimulus conditions in rats. Unpublished doctoral dissertation, Kent State University.

Olton, D. S., \& SAmUelson, R. J. (1976). Remembrance of places passed: Spatial memory in rats. Journal of Experimental Psychology: Animal Behavior Processes, 2, 97-116.

Overton, D. A. (1964). State-dependent or "dissociated" learning produced with pentobarbital. Journal of Comparative \& Physiological Psychology, 57, 3-12.

Parsons, P. J., Fagan, T., \& Spear, N. E. (1973). Short-term retention of habituation in the rat: A developmental study from infancy to old age. Journal of Comparative \& Physiological Psychology, 84, 545-553.

Perkins, C. C., JR. (1965). A conceptual scheme for studies of stimulus generalization. In D. I. Mostofsky (Ed.), Stimulus generalization (pp. 38-54). Stanford: Stanford University Press.

Perkins, C. C., JR., \& Weyant, R. G. (1958). The interval between training and test trials as a determiner of the slope of generalization gradients. Journal of Comparative \& Physiological Psychology, 51, 596-600.

Phillips, R. G., \& LeDoux, J. E. (1992). Differential contribution of amygdala and hippocampus to cued and contextual fear conditioning. Behavioral Neuroscience, 106, 274-285.

Postman, L. (1972). A pragmatic view of organization theory. In E. Tulving \& W. Donaldson (Eds.), Organization of memory (pp. 3-48). New York: Academic Press.

Pryce, C. R., Lehmann, J., \& Feldon, J. (1999). Effect of sex on fear conditioning is similar for context and discrete CS in Wistar, Lewis and Fischer rat strains. Pharmacology Biochemistry \& Behavior, 64, 753-759.

Pryce, C. R., Palme, R., \& Feldon, J. (2002). Development of pituitary- 
adrenal endocrine function in the marmoset monkey: Infant hypercortisolism is the norm. Journal of Clinical Endocrinology \& Metabolism, 87, 691-699.

Pugh, C. R., Fleshner, M., \& Rudy, J. W. (1997). Type II glucocorticoid receptor antagonists impair contextual fear but not auditorycue fear conditioning in juvenile rats. Neurobiology of Learning \& Memory, 67, 75-79.

Pugh, C. R., Tremblay, D., Fleshner, M., \& Rudy, J. W. (1997). A selective role for corticosterone in contextual-fear conditioning. Behavioral Neuroscience, 111, 503-511.

Riccio, D. C., ACKIL, J., \& Burch-Vernon, A. (1992). Forgetting of stimulus attributes: Methodological implications for assessing associative phenomena. Psychological Bulletin, 112, 433-445.

Riccio, D. C., Rabinowitz, V. C., \& Axelrod, S. (1994). Memory: When less is more. American Psychology, 49, 917-926.

Riccio, D. C., Richardson, R., \& EbneR, D. L. (1984). Memory retrieval deficits based upon altered contextual cues: A paradox. Psychological Bulletin, 96, 152-165.

Rosenfeld, P., Sutanto, W., Levine, S., \& de Kloet, E. R. (1988). Ontogeny of type I and type II corticosteroid receptors in the rat hippocampus. Brain Research, 470, 113-118.

Rovee-Collier, C. (1999). The development of infant memory. Current Directions in Psychological Science, 8, 80-85.

RudY, J. W. (1993). Contextual conditioning and auditory cue conditioning dissociate during development. Behavioral Neuroscience, 107, 887-891.

SAntucci, A. C., \& CARDIEllo, J. (2004). Memory reactivation in rats treated with the 5-HT $1 \mathrm{~A}$ agonist 8-OH-DPAT: A case of gone, but not forgotten. Behavioral Neuroscience, 118, 248-252.

SaPOlSky, R. M., \& MeAney, M. J. (1986). Maturation of the adrenocortical stress response: Neuroendocrine control mechanisms and the stress hyporesponsive period. Brain Research Reviews, 11, 65-76.

Sarrieau, A., Sharma, S., \& Meaney, M. J. (1988). Postnatal development and environmental regulation of hippocampal glucocorticoid and mineralocorticoid receptors. Developmental Brain Research, 43, 158-162.

Schulenburg, C. J., Riccio, D. C., \& Stikes, E. R. (1971). Acquisition and retention of a passive-avoidance response as a function of age in rats. Journal of Comparative \& Physiological Psychology, 74, 75-83.

Sмiтh, S. M. (1979). Remembering in and out of context. Journal of Experimental Psychology: Human Learning \& Memory, 5, 460-471.

Spear, N. E. (1973). Retrieval of memory in animals. Psychological Review, 80, 163-194.

SPEAR, N. E. (1978). The processing of memories: Forgetting and retention. Hillsdale, NJ: Erlbaum.
Spear, N. E., \& Parsons, P. (1976). Analysis of a reactivation treatment: Ontogeny and alleviated forgetting. In D. Medin, R. Davis, \& W. Roberts (Eds.), Processes of animal memory (pp. 135-165). Hillsdale, NJ: Erlbaum.

Spear, N. E., \& Riccio, D. C. (1994). Memory: Phenomena and principles. Boston: Allyn \& Bacon.

SpeAR, N. E., \& SMITH, G. J. (1978). Alleviation of forgetting in preweanling rats. Developmental Psychobiology, 11, 513-529.

Steinert, P. A., Infurna, R. N., \& Spear, N. E. (1980). Long-term retention of a conditioned taste aversion in preweanling and adult rats. Animal Learning \& Behavior, 8, 375-381.

Suengas, A. G., \& Johnson, M. K. (1988). Qualitative effects of rehearsal on memories for perceived and imagined complex events. Journal of Experimental Psychology: General, 117, 377-389.

Thomas, D. A., \& Riccio, D. C. (1979). Forgetting of a CS attribute in a conditioned suppression paradigm. Animal Learning \& Behavior, 7, 191-195.

Thomas, D. R., \& Lopez, L. J. (1962). The effects of delayed testing on generalization slope. Journal of Comparative \& Physiological Psychology, 55, 541-544.

Thomson, D. M., \& Tulving, E. (1970). Associative encoding and retrieval: Weak and strong cues. Journal of Experimental Psychology, 86, 255-262.

Tulving, E., \& Thomson, D. M. (1973). Encoding specificity and retrieval processes in episodic memory. Psychological Review, 80, 352-373.

UnDERWOOD, B. J. (1969). Attributes of memory. Psychological Review, 76, 559-573.

Van Oyen, H. G., Van de Poll, N. E., \& de Bruin, J. P. (1979). Sex, age and shock-intensity as factors in passive avoidance. Physiology \& Behavior, 23, 915-918.

Weingartner, H., Miller, H., \& Murphy, D. L. (1977). Mood-state dependent retrieval of verbal associations. Journal of Abnormal Psychology, 86, 276-284.

Zhou, Y. L., \& Riccio, D. C. (1994). Pretest cuing can alleviate the forgetting of contextual stimulus attributes. Learning \& Motivation, 25, 233-244.

Zhou, Y. [L.], \& Riccio, D. C. (1996). Manipulation of components of context: The context shift effect and forgetting of stimulus attributes. Learning \& Motivation, 27, 400-407.

(Manuscript received September 8, 2004; revision accepted for publication January 21, 2005.) 